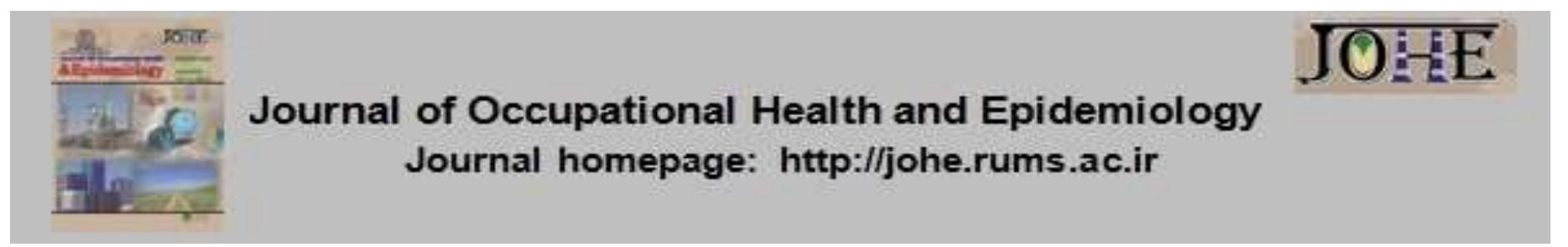

\title{
Occupational and organizational consequences of perception of perceived organizational justice and support among faculty members in West Azerbaijan Province, Iran, in 2017
}

\author{
Amir Hemmati ${ }^{1}$, Behnam Talebi ${ }^{*}$, Jahangir Yari ${ }^{3}$, Mohammad Hassani $^{3}$ \\ 1- PhD Student in Educational Administration, Department of Educational Sciences, Tabriz Branch, Islamic Azad University, Tabriz, \\ Iran. \\ 2- Assistant Prof., Department of Educational Sciences, Tabriz Branch, Islamic Azad University, Tabriz, Iran. \\ 3- Professor, Department of Educational Sciences, Faculty of Literature and Humanities, Urmia University, Urmia, Iran.
}

Citation: Hemmati A, Talebi B, Yari J, Hassani M. Occupational and organizational effects of
perception of perceived organizational justice and support among faculty members in West
Azarbaijan Province, Iran, in 2017. JOHE. 2018; 7(3):174-84.

\section{Article Info \\ * Corresponding authors: Behnam Talebi, \\ E-mail:}

btalebi1351@yahoo.com

\section{Article history}

Received: Feb, 2018

Accepted: Jul, 2018

10.29252/johe.7.3.174

Print ISSN: 2251-8096 Online ISSN: 2252-0902

Peer review under responsibility of Journal of Occupational Health and Epidemiology

\section{Abstract}

Background: Since human resources is the most important asset of each organization, and its effective management is the key to the success of organization, this study aimed to investigate the occupational and organizational consequences of perception of perceived organizational justice and support among faculty members of Islamic Azad University in West Azerbaijan Province, Iran.

Materials and Methods: In this descriptive study, among 747 faculty members, 300 were selected through proportionate stratified random sampling method using Morgan table. The collected data were analyzed using path analysis and structural equation modeling methods.

Results: Organizational support and perception of organizational justice had, respectively, a direct and significant association with organizational citizenship behavior $(\beta=0.25, T=$ 4.70) $(\beta=0.24, T=4.62)$, job satisfaction $(\beta=0.29, T=5.71)(\beta=0.31, T=5.64)$, job performance $(\beta=0.22, T=4.30)(\beta=0.31, T=5.98)$, organizational commitment $(\beta=$ $0.21, T=3.91)(\beta=0.20, T=3.74)$, and an inverse significant association with turnover intention $(\beta=-0.21, T=-3.85)(\beta=-0.16, T=-3.03)$ and absenteeism $(\beta=-0.99, T=-$ 3.63) $(\beta=-0.21, T=-3.90)$.

Conclusions: Based on the findings, it can be concluded that any increase in perceived organizational support and perception of organizational justice leads to an increase in organizational behavior, job satisfaction, job performance, and organizational commitment, as well as reduction in turnover intention and absenteeism among faculty members.

Keywords: Perception, Job Satisfaction, Job Performance, Iran.

\section{Introduction}

Currently, the importance of human resource management must be considered in the success of any organization including the university. Faculty members play a vital role in this regard, and are among the key factors for differentiating the success factor in various organizations, especially the university. Based on the research conducted by Shafie et al., faculty members provide goals and give life to the organization; in addition, the main challenge, presently, for many universities is the recruitment, retention, management, and deriving the satisfaction of members who can help increase the university's effectiveness. The profound study of the principles in management research shows that productive organizational performance has a direct relation to the level of motivation and commitment of employees in the organization. The motivation of 
the members is affected by the workplace, and is shaped by numerous factors (1).

Perceived organizational support is defined as an extent to which employees believe that their work organization values their contribution, and cares about their well-being. Perceived organizational support is usually described by the theory of social exchange. Social exchanges at the core of the psychological processes are perceived as consequences of organizational support $(2,3)$. When the organization provides the support and resources required, the function, in turn compensates it through efforts such as commitment and citizenship behavior. Therefore, the norm of mutual action leads to employee participation in citizenship behaviors that contributes in general to the organization's well-being. An increasing number of studies have shown that perceived organizational support is positively associated with organizational citizenship behavior $(4,5)$.

Organizational justice, and how it is managed, is one of the key factors affecting human resource behavior. Organizational justice occurs when people realize that they are treated fairly and equally in the workplace. Well-known psychologists also emphasize that, in social exchanges, fairness leads to motivation production. People compare themselves with the actions of others to determine whether they are treated fairly or not. Organizational justice cannot be ignored, because it is the main source of motivation for members $(6,7)$.

According to Colquitt et al., organizational justice has drawn much attention in management and psychological research (8). Organizational justice means that employees observe that the organizational behavior is fair. Based on the previous researches by different researchers and scholars (9-13), it has been discovered that there are three forms of organizational justice, distributive, procedural, and interactional justice. Distributive justice, as described by McDowall and Fletcher, is a term that describes the perceived justice of the consequences that people receive. Procedural justice is defined as individuals' perceptions of methods on which consequences depend (9). Bies and Moag have defined interactive justice as the quality of interpersonal interactions of organizational decision makers during organizational processes (13). These three dimensions of justice interacting with each other formulate perceived justice for people in the workplace. According to the theory of justice, distributive, procedural, and interactive justice information has been processed for the purpose of constructing and reforming the entire justice judgment. Based on this theory, some other attitudes such as job satisfaction, organizational citizenship behavior, organizational commitment, organizational trust, and aggressive behavior are also affected by organizational justice (10-13).

Faculty members, who have higher job satisfaction in their work, also have a higher performance, attitude toward their work, and a higher sense of empowerment (14). Inversely, the turnover intention, which is of the consequences of job dissatisfaction, is high among faculty members in universities (15). Moreover, job satisfaction, as a job empowerment outcome, is effective in determining the members' absenteeism and turnover intention, meaning that the more satisfied the members and employees are with their job, the less likely they are to be absent from work (16). Employees, who are loyal and satisfied, and their actions are consistent with the organization's goals and values, desire to preserve their organization membership, and ready to go beyond their own tasks. These human resources can be a major factor in the effectiveness of organization. The presence of such resources in organization brings with it high performance, and the reduction of absenteeism, delays, and abandonment (17). Faculty members, who are psychologically more affiliated with the organization, are more productive and satisfied. This component is associated with the job performance of the members and their ability to innovate and integrate new ideas in the work; meaning that when the member's commitment to the university is high, its results for the university is better organizational citizenship behavior, high job performance, and reduction of absenteeism and turnover intention (18). The results of previous studies have proved that organizational commitment is related to the outcomes of job satisfaction and job performance. Committee members are less likely to change their job, and are more likely to have a higher level of performance (19).

Based on the theoretical foundations and the history of research on the subject, it can be said that faculty members' perception of their organization's justice in organization and organizational support can have a positive effect on their job performance as well as their organizational commitment, job satisfaction, and citizenship behavior. Moreover, it can reduce the tendency to leave the job and absence from work at the university. The present research sought to determine whether organizational justice and perceived organizational support impact organizational citizenship behavior, job satisfaction, organizational commitment, job performance, the desire to leave a job, and absenteeism among university faculty members. Based on what has been stated, the conceptual and theoretical model of occupational and organizational effects on faculty 
members' perceptions of perceived organizational justice and organizational support is as figure 1.

The proposed structural model shows the direct association of perception of perceived organizational justice and support with the faculty members' occupational and organizational consequences.

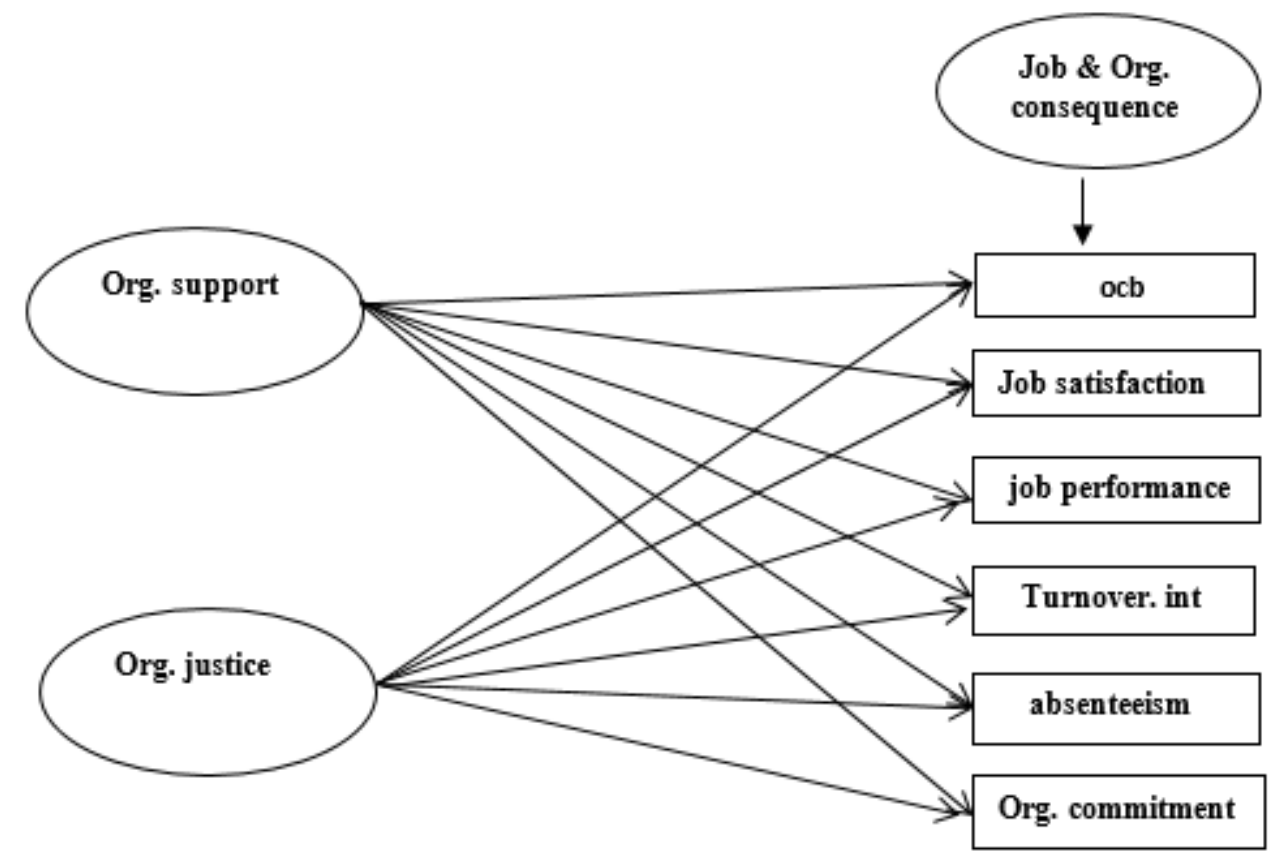

Figure 1: Conceptual Model of Research

\section{Materials and Methods}

In the analytical model of the current research, organizational justice and organizational support were predictor variables and citizenship behavior, job performance, job satisfaction, organizational commitment, absenteeism, and turnover intention were criterion variables. The statistical population of the research consisted of all 747 faculty members of the Islamic Azad University in West Azerbaijan Province, Iran, in the academic year of 2016-2017. The sample size was considered to be 300 individuals based on the Morgan table. According to the Morgan table, out of 747 subjects, more than 256 individuals were required for sampling. In this study, 300 individuals were considered as participants. The questionnaires were distributed among 330 people, of which 300 were collected. The sampling method used to collect data was proportionate stratified random sampling. First, the faculty members of the Islamic Azad University in West Azerbaijan Province were divided into three sections according to the normal division of the province (the north, south, and center of the province). Then, the number of faculty members in the three regions was calculated. Finally, the number of faculty members from different universities according to the ratios of the different universities of each unit in different cities of each region and according to the sample size was obtained. The distribution of the questionnaires in the final stage at the university level was administered randomly. The data collection tools consisted of a demographic characteristics form, 7 standard questionnaires, and 1 researcher-made questionnaire. The demographic characteristics form included questions on age (35 to 65 years), gender, work experience (between less than 5 years and more than 15 years), and academic rank (instructor, assistant professor, associate professor, and professor). It should be noted that all questionnaires were scored based on a five-point Likert scale (with options: 1 = strongly opposed, 2 = I disagree, $3=$ no opinion, $4=1$ agree, and $5=1$ totally agree). It should also be noted that the researcher started to distribute questionnaires in each unit after obtaining permission from the province department of Urmia Islamic Azad University. The sample size for each university unit is given in table 1 . 
Table 1: Frequency distribution of the statistical population and sample by units of the university and the scientific ranking of faculty members of Islamic Azad University of West Azarbaijan Provice, Iran, in 2017

\begin{tabular}{ccccccc}
\hline \multirow{2}{*}{ University units } & \multicolumn{9}{c}{ Faculty members } & Total & Sample number \\
\cline { 2 - 6 } & Professor & $\begin{array}{c}\text { Associate } \\
\text { Professor }\end{array}$ & $\begin{array}{c}\text { Assistant } \\
\text { Professor }\end{array}$ & Instructor & \\
\hline Urmia & 7 & 15 & 91 & 104 & 217 & 87 \\
\hline Mahabad & 4 & 6 & 75 & 101 & 186 & 74 \\
\hline Khoy & 1 & 1 & 55 & 62 & 119 & 47 \\
\hline Salmas & - & - & 11 & 35 & 46 & 19 \\
\hline Naqadeh & - & - & 6 & 23 & 29 & 12 \\
\hline Makoo & - & - & 8 & 31 & 39 & 15 \\
\hline Bokan & - & - & 5 & 25 & 29 & 12 \\
\hline Shahindejh & - & - & - & 9 & 9 & 4 \\
\hline Miandoab & - & - & 11 & 49 & 60 & 25 \\
\hline Piranshahr & - & - & - & 8 & 8 & 3 \\
\hline Qara Ziauddin & - & - & 1 & 4 & 5 & 2 \\
\hline Total & 12 & 22 & 263 & 450 & 747 & 300 \\
\hline
\end{tabular}

To collect data, Perceived Organizational Support Questionnaire (POSQ) (Rhoades and Eisenberger) (2), Colquitt's Organizational Justice Scale (8), Organizational Citizenship Behavior Questionnaire (Organ and Konovsky) (20), Organizational Commitment Questionnaire (OCQ) (Porter) (21), Job Satisfaction Questionnaire (Linz) (22, 23), Turnover Intention Questionnaire (Leungo and Moura) (24), Job Performance Questionnaire (Patterson) (25), and the researcher-made Absenteeism Questionnaire. In the 8-question questionnaire, the total score obtained ranged from 8 to 40 , with the range of 5-10 points representing the lowest score and 30-40 points the highest score. A score of 20 illustrated low satisfaction and a score of 40 indicated high satisfaction.

Perceived Organizational Support Questionnaire: In the current study, to measure perceived organizational support, the POSQ was used (2). This questionnaire contains 8 items. The items are scored based on a 5-point Likert scale ranging from 1 (strongly disagree) to 5 (strongly agree). In this questionnaire, scores of 10-20 and 30-40 represent the lowest and the highest organizational support, respectively. Rhoades and Eisenberger reported the validity of this questionnaire as 0.81 using Cronbach's alpha. Moreover, the reliability of this questionnaire was reported as 0.55 by Rhoades and Eisenberger which was found to be significant at $\mathrm{P}<0.1$, and this shows the favorable reliability of the questionnaire. In addition, the reliability of the questionnaire in this research through its implementation on 30 faculty members, and before its main implementation, was calculated as 0.71 using Cronbach's alpha.

Organizational Justice Scale: Colquitt's Organizational Justice Scale has 20 questions which are rated on a 5-point Likert scale ranging from (very little) to 5 (very much). This questionnaire which was made by Colquitt consists of the 4 dimensions of procedural justice (questions 109 to 115), distributive justice (questions 161 to 123), interpersonal justice (questions 120 to 123), and information justice (questions 124 to 128). In this questionnaire, the total scores of 20 to 40 and 80 to 100 indicate the lowest and the highest level of justice in the organization, respectively, in each aspect of organizational justice (distributive, procedural, interpersonal, and information justice). The reliability of this questionnaire is acceptable (8). The reliability of this questionnaire was calculated as 0.92 in the present research using Cronbach's alpha through its implementation on 30 faculty members, and before its main implementation.

Organizational Citizenship Behavior Questionnaire: This questionnaire was used to measure the employee's organizational citizenship behavior. This questionnaire is a modified questionnaire, taken from Smith et al. study (20) and adapted from the work of Organ and Konovsky. It contains 16 questions and is scored based on a 5-point Likert scale ranging from 1 (strongly disagree) to 5 (strongly agree). The questionnaire includes 5 components of organizational citizenship behavior (altruism, conscience, chivalry, literacy, and civil behavior). In this questionnaire, scores of 15 to 30 and scores between 70 and 80 represent the lowest and the highest citizenship behavior, respectively. Organ and Ryan, in their study, reported the reliability of this questionnaire to be between 0.89 and 0.91 through Cronbach's Alpha method (15). The reliability of the questionnaire in this research through its implementation on $\mathbf{3 0}$ faculty members, and before its main implementation, was calculated as 0.94 using Cronbach's alpha.

Organizational Commitment Questionnaire: To determine the level of organizational commitment, Porter's OCQ (21) was used which consists of 15 questions. This instrument is rated based on a 5point Likert scale ranging from 1 (strongly disagree) 
to 5 (strongly agree). This questionnaire includes 3 components of organizational commitment (emotional, normative, and continuous). In the $O C Q$, the scores of 15 to 30 and between 60 and 75 represent the lowest and the highest commitment to the organization, respectively. The reliability of the questionnaire in this research through its implementation on 30 faculty members, and before its main implementation, was calculated as 0.87 using Cronbach's alpha.

Job Satisfaction Questionnaire: This questionnaire was designed by Linz to measure job satisfaction, and its purpose is to examine and evaluate job satisfaction in organizations (22). This questionnaire contains 13 questions, is rated on a 5-point Likert scale ranging from 1 (strongly disagree) to 5 (strongly agree), and has a general score without components. In this questionnaire, a score between 10 and 25 indicates the lowest satisfaction and a score between 50 and 65 represents the highest satisfaction with the organization. The reliability of the Job Satisfaction Questionnaire was 0.858 in the research performed by Asghari et al. In addition, in this study, to examine the validity of the tool the main components analysis method was used, and the validity of the tool was found to be acceptable (23). The reliability of the questionnaire in this research, through its implementation on 30 faculty members, and before its main implementation, was calculated as 0.78 using Cronbach's alpha.

Turnover Intention Questionnaire: The standard Turnover Intention Questionnaire consists of the 2 components considered for turnover intention, the feeling of working with the organization (the amount of employee's loyalty and his attention to the organization's fate) and the decision to leave the organization (the employee's intention to leave their current job and look for a new one). This questionnaire contains 9 questions and is rated on a 5-point Likert scale ranging from 1 (strongly disagree) to 5 (strongly agree). In this questionnaire, scores of 10 to 20 and of 30 to 45 indicate the least and the highest tendency to leave the organization, respectively. In the research conducted by Raufi Sangachin, content validity was used to determine the validity of the questionnaire (24). The reliability of the questionnaire was calculated as 0.85 in this research using Cronbach's alpha through its implementation on 30 faculty members, and before its main implementation.Job Performance Questionnaire: This questionnaire consists of 15 questions and was prepared by Paterson and translated by Arshadi and
Shakkarshekan into Persian (25). This questionnaire is scored based on a 5-points Likert scale ranging from 1 (very little) to 5 (very much). This questionnaire includes 4 components of job performance (discipline, responsibility, cooperation, and job improvement). In this questionnaire, scores of $15-30$ and of $60-75$, respectively, represent the lowest and highest job performance in the organization. To determine its reliability, Cronbach's alpha coefficient was calculated which was 0.74 for job performance, showing the good reliability of the measurement tool.Absenteeism Questionnaire: This researcher-made questionnaire was scored on a 5-point Likert scale ranging from 1 (strongly disagree) to 5 (strongly agree). In this questionnaire, the scores of 5-10 and 20-25 represent the least and the most absenteeism in the organization, respectively. The reliability of this questionnaire was calculated as 0.81 in the present research using Cronbach's alpha through its implementation on 30 faculty members, and before its main implementation. Its validity has also been assessed and verified based on content validity through interviews with specialists.

Considering the fact that the statistical population consisted of the faculty members of Islamic Azad University in West Azerbaijan Province, after obtaining the necessary license from the university research unit, a letter of introduction was obtained from the province for the implementation of questionnaires in each department of Islamic Azad University of Urmia, Iran. Then, coordination with the Department of Public Security of the university was carried out in order to distribute the questionnaires among the faculty members of the universities. In each university, after explaining the subject of research to the participants, assuring them of the confidentiality of the data, and obtaining informed consent from them, the questionnaires were distributed among them. The assistant director of education of the university introduced the experts to accelerate their distribution. Finally, 300 questionnaires were returned and used in the statistical analysis.

To analyze the obtained data, confirmatory factor analysis, path analysis, and structural equation modeling methods were used at a significant level of 0.05 (Table 2). The data were analyzed using descriptive tests in SPSS software (version 20, IBM Corporation, Armonk, NY, USA) and using software-based structural equations modeling in LISREL III software (version 3, Scientific Software International Inc., Chicago, IL, USA). 
Table 2: Reliability of the research scales based on Cronbach's alpha

\begin{tabular}{ccc}
\hline & Variable & Cronbach's alpha \\
\hline $\mathbf{1}$ & Organizational support & 0.71 \\
\hline $\mathbf{2}$ & Organizational citizenship behavior & 0.94 \\
\hline $\mathbf{3}$ & Organizational commitment & 0.87 \\
\hline $\mathbf{5}$ & Job satisfaction & 0.78 \\
\hline $\mathbf{6}$ & Turnover intention & 0.85 \\
\hline $\mathbf{7}$ & Absenteeism & 0.81 \\
\hline $\mathbf{8}$ & Job performance & 0.74 \\
\hline
\end{tabular}

\section{Results}

From among the 300 participants, 218 (72.7\%) were men and $82(27.3 \%)$ were women. The data related to the rank of faculty members showed that out of the 300 individuals who filled out the questionnaire, 161 (53.6\%) were instructors, 128 (42.6\%) assistant professors, $6(2 \%)$ associate professors, and 5 $(1.6 \%)$ were professors. The data related to the educational level of the sample showed that 98 (32.6\%) participants were postgraduates and 202 $(67.3 \%)$ were $\mathrm{PhD}$ graduates. Furthermore, the data on the work experience of the faculty members, as the research sample, indicated that 98 (32.6\%) participants had less than 5 years, 155 (51.6\%) had between 6-15 years, and 47 (15.6\%) had more than 15 years of work experience. The highest frequency was observed in the work experience of 6 to 15 years.

Based on table 3 , it was found that the highest mean (4.26) was related to the performance variable and the lowest mean (2.41) was related to the turnover intention variable.

Table 3: Mean and standard deviation of the studied variables among faculty members of Islamic Azad University, West Azerbaijan Province, Iran

\begin{tabular}{lccc}
\hline \multicolumn{1}{c}{ Variable } & Sample No. & Mean \pm SD & Minimum-Maximum \\
\hline Organizational support & 300 & $3.23 \pm 0.50$ & $1.50-4.75$ \\
\hline Organizational justice & 300 & $3.45 \pm 0.59$ & $1.70-4.65$ \\
\hline Organizational citizenship & 300 & $3.65 \pm 0.35$ & $2.69-4.63$ \\
\hline Job satisfaction & 300 & $4.06 \pm 0.47$ & $2.62-4.56$ \\
\hline Job performance & 300 & $4.26 \pm 0.46$ & $2.59-4.70$ \\
\hline Turnover intention & 300 & $2.41 \pm 0.60$ & $1.22-2.78$ \\
\hline Absenteeism & 300 & $2.53 \pm 0.54$ & $1.00-2.67$ \\
\hline Organizational commitment & 300 & $3.49 \pm 0.38$ & $2.47-4.73$ \\
\hline
\end{tabular}

According to the results presented in table 4 and the significant levels of each variable of the study that was greater than 0.05 , the data for all variables was normal.

Table 4: One-sample Kolmogorov-Smirnov test results

\begin{tabular}{lll}
\hline \multicolumn{1}{c}{ Variable } & $\mathbf{z}$ & Significant level \\
\hline Perceived organizational support & 1.43 & 0.086 \\
\hline Perceived organizational justice & 1.47 & 0.071 \\
\hline Organizational citizenship behavior & 1.35 & 0.051 \\
\hline Job satisfaction & 1.29 & 0.007 \\
\hline Job performance & 1.04 & 0.064 \\
\hline Turnover intention & 1.56 & 0.008 \\
\hline Absenteeism & 1.77 & 0.095 \\
\hline Organizational commitment & 1.55 & 0.080 \\
\hline
\end{tabular}

Based on the results of correlation coefficient test (Table 5), the correlation of perceived organizational support and perception of organizational justice with other variables was significant [organizational citizenship behavior $(0.47$ and 0.48 , respectively), job satisfaction ( 0.34 and 0.56 , respectively), job performance $(0.26$ and 0.30 , respectively), turnover intention $(-0.23$ and -0.27 , respectively), absenteeism (-0.33 and -0.29 , respectively), organizational commitment ( 0.56 and 0.34, respectively)]. Among the studied variables, the highest correlation was found between the faculty members' perceived organizational support and their perception of organizational justice, and organizational citizenship behavior. The least correlation was between perceived organizational support and perception of organizational justice, and turnover intention. 
Table 5: Correlation matrix between research variables

\begin{tabular}{|c|c|c|c|c|c|c|c|c|}
\hline & 1 & 2 & 3 & 4 & 5 & 6 & 7 & 8 \\
\hline Organizational support & 1 & & & & & & & \\
\hline Organizational justice & 0.036 & 1 & & & & & & \\
\hline $\begin{array}{l}\text { Organizational Citizenship } \\
\text { Behavior }\end{array}$ & 0.048 & 0.047 & 1 & & & & & \\
\hline Job satisfaction & 0.056 & 0.034 & 0.063 & 1 & & & & \\
\hline Job performance & 0.030 & 0.026 & 0.044 & 0.036 & 1 & & & \\
\hline Turnover intention & 0.038 & 0.040 & 0.038 & 0.034 & 0.025 & 1 & & \\
\hline Absenteeism & -0.033 & -0.027 & -0.026 & -0.022 & -0.018 & -0.020 & 1 & \\
\hline Organizational commitment & 0.036 & -0.029 & -0.036 & -0.027 & -0.022 & -0.028 & 0.039 & 1 \\
\hline
\end{tabular}

Perceived organizational support was effective on faculty members' citizenship behavior, job performance, job satisfaction, organizational commitment, absenteeism, and turnover intention. In the figures 2 and 3 , the software output is shown based on standard coefficients and T coefficients. In order to better understand of the associations of the variables and the effect of perceived organizational support on organizational citizenship behavior, job performance, job satisfaction, organizational commitment, absenteeism, and turnover intention of the faculty members, path analysis-structural equation modeling was used.

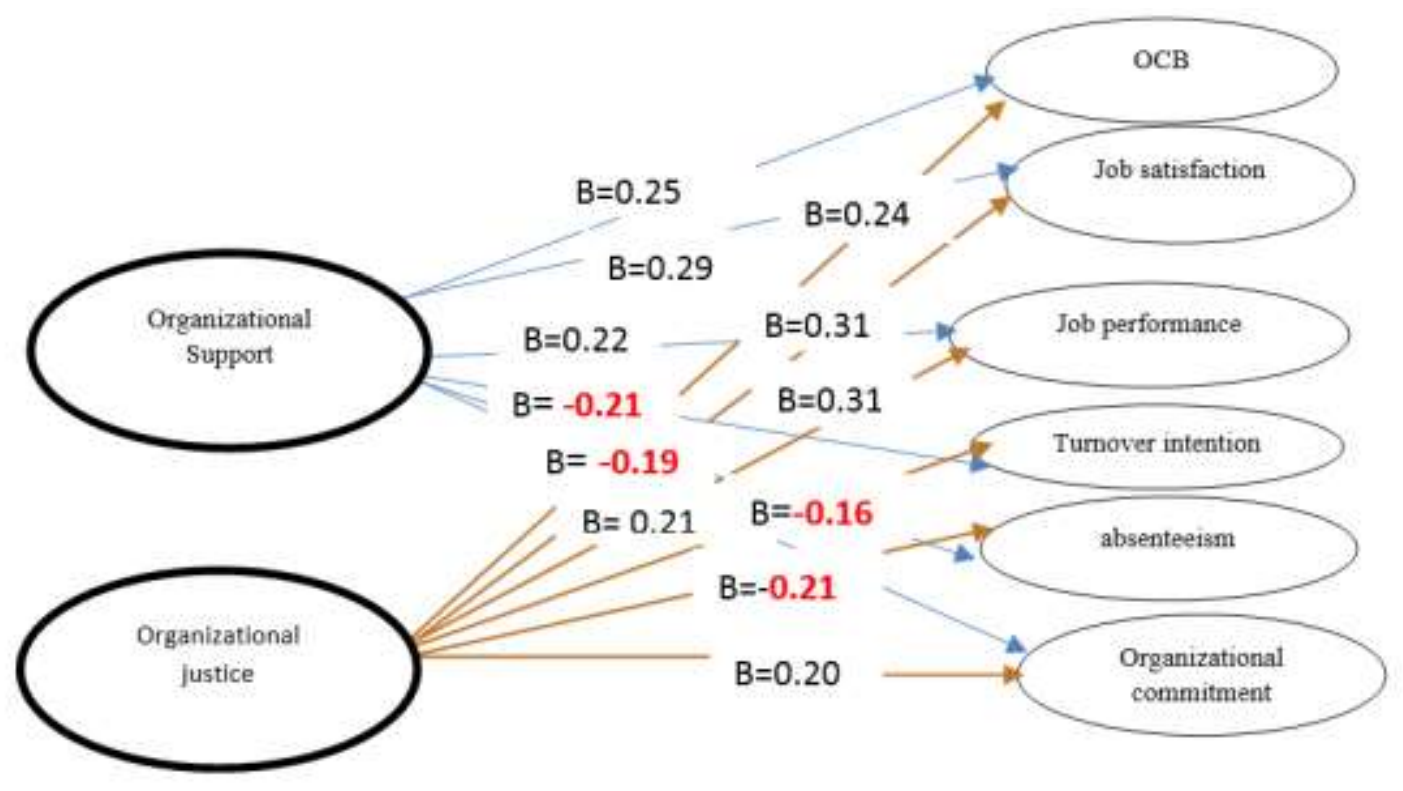

Chi-Square $=65.66, \mathrm{df}=24, \mathrm{P}$-value $=0.00001, \mathrm{RMSEA}=0.076$

Figure 2: Standard coefficients of structural associations between the research variables

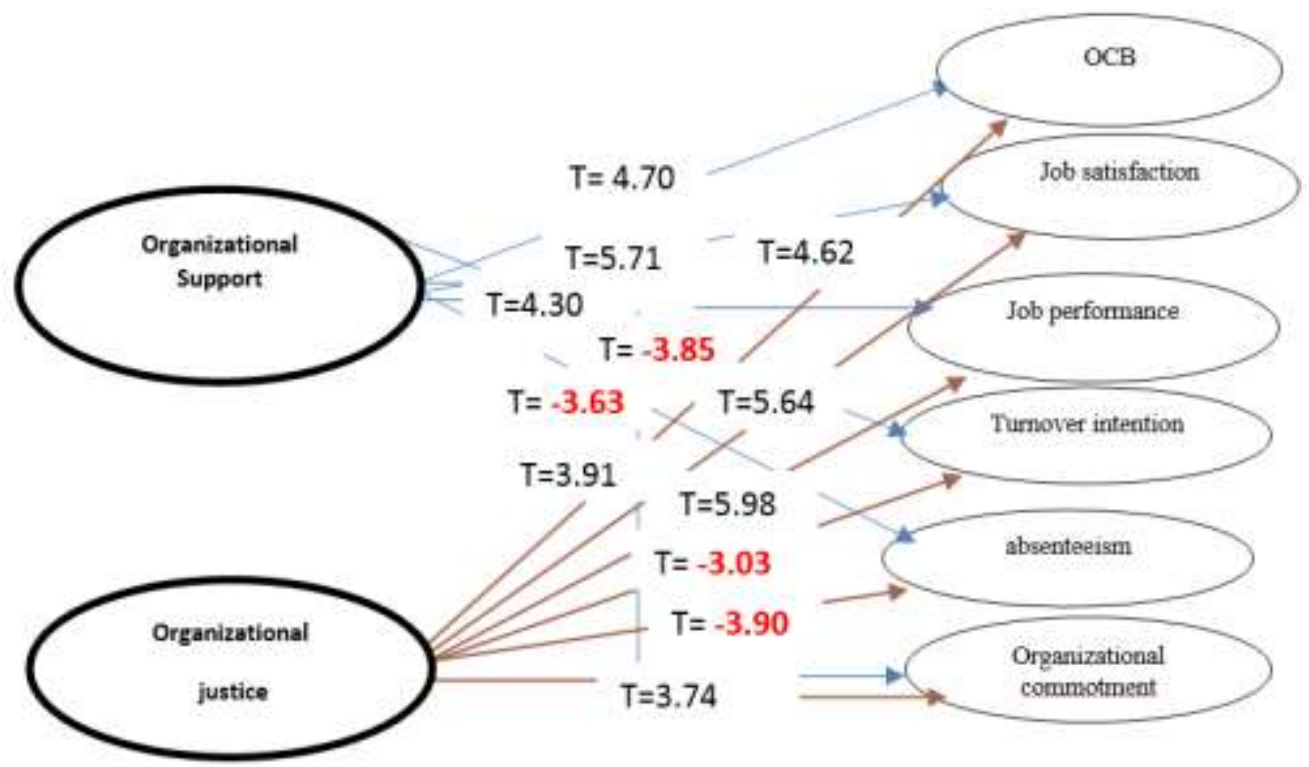

Chi-Square $=65.66, \mathrm{df}=24, \mathrm{P}$-value $=0.00001, \mathrm{RMSEA}=0.076$

Figure 3: T-coefficients of structural associations between the research variables 
Based on the results, the chi-square index was 65.66 and the root mean square error estimate (RMSEA) in this model was 0.07. Comparative fit indices (CFI), normal fit index (NFI), normally fitted index (NNFI), incremental fitness index (IFI), and relative goodwill index (RFI) were 0.95, 0.94, 0.93, 0.95 , and 0.91 , respectively. Given that the values of these indices are above 0.9 , it can be seen that the structural model has an optimal fit. One of the features of structural equation modeling is to estimate the direct and indirect effects of variables on each other. This feature allows researchers to examine the role of variables in the model.

According to the results presented in table 6 , in terms of the direct effects of organizational support and organizational justice on organizational and occupational consequences, all routes are significant at 0.001 .

Table 6: Estimation of direct effect coefficients

\begin{tabular}{|c|c|c|c|}
\hline Variables & Path coefficient & t-statistic & Level of significance \\
\hline \multicolumn{4}{|c|}{ On citizenship behavior } \\
\hline Support & 0.250 & 4.70 & 0.001 \\
\hline Justice & 0.240 & 4.62 & 0.001 \\
\hline \multicolumn{4}{|l|}{ On satisfaction } \\
\hline Support & 0.290 & 5.71 & 0.001 \\
\hline Justice & 0.310 & 5.64 & 0.001 \\
\hline \multicolumn{4}{|l|}{ On performance } \\
\hline Support & 0.220 & 4.30 & 0.001 \\
\hline Justice & 0.310 & 5.98 & 0.001 \\
\hline \multicolumn{4}{|l|}{ On turnover intention } \\
\hline Support & -0.210 & -3.85 & 0.001 \\
\hline Justice & -0.160 & -3.03 & 0.001 \\
\hline \multicolumn{4}{|l|}{ On absenteeism } \\
\hline Support & -0.190 & -3.63 & 0.001 \\
\hline Justice & -0.210 & -3.90 & 0.001 \\
\hline \multicolumn{4}{|l|}{ On commitment } \\
\hline Support & 0.210 & 3.91 & 0.001 \\
\hline Justice & 0.200 & 3.74 & 0.001 \\
\hline
\end{tabular}

The findings of this analysis verified the findings and results of the path analysis, and direct effects in the structural model related to the research hypotheses. As the standard estimates as well as significant numbers relate to path analysis of research hypotheses in the software output shown in table 7 , the values of the fit indices indicate that the model was well-processed.

Table 7: Estimation of direct effect and indirect effect coefficients and mediation review

\begin{tabular}{llccc}
\hline \multicolumn{2}{c}{ hypothesis with path analysis } & Standard path coefficient & t & Result \\
\hline Organizational justice & $\longrightarrow$ Citizenship behavior & 0.24 & 4.62 & DE \\
\hline Organizational justice & $\longrightarrow$ Commitment & 0.20 & 3.74 & DE \\
\hline Organizational justice & $\longrightarrow$ Satisfaction & 0.29 & 5.64 & DE \\
\hline Organizational justice & $\longrightarrow$ Performance & 0.31 & 5.98 & DE \\
\hline Organizational justice & $\longrightarrow$ Turnover & -0.16 & -3.03 & DE \\
\hline Organizational justice & $\longrightarrow$ Absenteeism & -0.21 & -3.90 & DE \\
\hline Organizational support & $\longrightarrow$ Citizenship behavior & 0.25 & 4.70 & DE \\
\hline Organizational support & $\longrightarrow$ Commitment & 0.21 & 3.91 & DE \\
\hline Organizational support & $\longrightarrow$ Satisfaction & 0.29 & 5.71 & DE \\
\hline Organizational support & $\longrightarrow$ Performance & 0.22 & 4.30 & DE \\
\hline Organizational support & $\longrightarrow$ Turnover & -0.21 & -3.85 & DE \\
\hline Organizational support & $\longrightarrow$ Absenteeism & -0.19 & -3.63 & DE \\
\hline DE: direct effect & & & & \\
\hline
\end{tabular}

\section{Discussion}

The current research was carried out with the purpose of examining the impact of perceived organizational support on organizational citizenship behavior, job performance, job satisfaction, organizational commitment, absenteeism, and turnover intention among the faculty members of
Islamic Azad University in West Azerbaijan Province.

The results indicate the direct effect of perceived organizational justice and support on organizational citizenship behavior, job performance, job satisfaction, organizational commitment, absenteeism, and turnover intention among the faculty members. According to the results of the 
statistical test, the coefficient of influence and the corresponding t-value of organizational justice on citizenship behavior, satisfaction, performance, turnover intention, absenteeism, and commitment was 0.24 and $4.62,0.29$ and 5.64, 0.31 and 5.98, 0.16 and $-03.03,-0.21$ and -3.90 , and 0.20 and 3.74 , respectively. Since the t-statistic corresponding with these paths is significant at 0.01 and 0.05 , it can be said that organizational justice had a direct and positive effect on citizenship behavior, job performance, job satisfaction, and organizational commitment while it had an inverse direct effect on absenteeism and turnover intention among the members.

The findings of the present study corresponded with the findings of studies conducted inside the country by Heidari et al. (26), Yousefi Majd et al. (27), Hassani and Jodatkordlar. (28), Sargazi and Balaghat (29), and Farzanjou et al. (30). They were also in agreement with the findings of researches conducted abroad by Muqadas et al. (31), Titrek et al. (32), AL-Gharaibeh and Albdareen (33), Lim and Loosemore (34), Lee et al. (35), and Akram et al. (36). It is worth noting that no research was found of which the results were inconsistent with those of the present study. It should be noted that the significance of the impact of the perception of organizational justice on business and organizational consequences in all societies examined has shown that the significance of the perceived effects of organizational justice on societies is unaffected by this association. The more equitable the fairness of the organization is, the more the faculty members will recognize organizational fairness, their behavior, their job performance, their job satisfaction, their organizational commitment to the organization, and their absence from and willingness to leave their job. In contrast, members who feel less in the organization will show lower levels of behavior, job performance, job satisfaction, and organizational commitment; on the other hand, they will show higher levels of absenteeism and a desire to leave the organization.

In explaining the results, it can be said that when members of the organization observe injustice, they are more likely to abandon the organization which, in turn, leads to absenteeism and turnover intention. Moreover, reduction in organizational commitment, job satisfaction, citizenship behavior, and job performance may occur. These outcomes will influence the entire organization because committed members, who are interested in their job and its performance, provide the grounds for growth and development in the organization. However, those with less commitment and interest, and poor performance are neutral to the organization's issues and problems, and do not feel committed and responsible, as a result, they leave the organization unsuccessful in achieving its goals.

Furthermore, based on the results of the statistical test, the coefficient of influence and the corresponding t-value of the effect of perceived organizational support on citizenship behavior, satisfaction, performance, turnover intention, absenteeism, and commitment were 0.25 and 4.70 , 0.29 and $5.71,0.22$ and $4.30,-0.21$ and $-3.85,-0.19$ and -3.63 , and 0.21 and 3.91 , respectively. The findings of the studies carried out inside and outside the country corresponded with our findings, studies conducted by Naderi et al. (37), Hosseini kohkamari et al. (38), Valipoor (39), Hsiao et al. (40), Kurtessis et al. (41), and Kaffashpor et al. (42). Kwan et al. (43) have studied industrial workers and their findings were not in agreement with that of Casper et al. (44) due to the discrepancy between their statistical populations.

The staff or faculty members of the statistical community make up for the effects of perceived support and organizational justice with meaningful occupational and organizational outcomes. Therefore, it can be said that organizational support has a positive significant relation with citizenship behavior, job performance, job satisfaction, and organizational commitment, while it has a significant inverse relation with absenteeism and turnover intention. The more the faculty members perceive organizational support, the more their perception of organizational support will develop a sense of belonging in the faculty members, which will lead to the improvement of their citizenship behavior, job performance, job satisfaction, and organizational commitment. In explaining the results, it can be said that the more the members perceive support from their organization, the more their citizenship behavior, job satisfaction, job performance, and organizational commitment will be affected. Thus, members will increase their job performance, illustrate positive citizenship behaviors in the organization, and be more satisfied and committed to their organization which, in turn, will create the grounds for growth and development in the organization and human resources. Human resources with a high level of organizational support will provide the organization with excellence and scientific growth, and make the organization succeed in achieving its mission. Inversely, human resources with a low and false level of organizational support will leave the organization unsuccessful in achieving its mission (scientific development, and etc.) and provide the basis for scientific paralysis.

In the end, both theoretical and research foundations and the present research confirmed the 
impact of perceived organizational justice and perceived organizational support on job and organizational consequences. Nevertheless, it is more important to know how the tools used to measure variables in the research are validated.

The limitations of this research include the lack of cooperation of some faculty members in the implementation and delivery of the questionnaires, the existence of a conservative attitude in organizational environments, the lack of a dominant research spirit among some faculty members, and the lack of literature in this regard. Little is said about the association between research variables and the lack of access to broad theoretical foundations. In this regard, some issues can be identified in the context of this article for future research. The following suggestions can add to the richness of further research in this field. It is necessary to further study the impact of perceived organizational justice and perceived organizational support on other variables of occupational and organizational outcomes, and use other tools. It is suggested that other roles of moderators in the association of the effects of perceptions of organizational justice and perceived organizational support with business and organizational implications be considered.

\section{Conclusion}

Based on the results of this study, it can be concluded that perceived organizational support and perception of organizational justice are effective in promoting organizational citizenship behavior, job satisfaction, job performance, and organizational commitment, as well as reducing turnover intention and absenteeism.

\section{Acknowledgement}

We thank all faculty members of the Islamic Azad University in West Azerbaijan Province for their cooperation, the authorities of these universities for their coordination in collecting the data, and all those who collaborated in this research. This article is based on the PhD thesis by Amir Hemmati, the doctoral student of the Department of Educational Sciences in Tabriz Branch, Islamic Azad University, Tabriz, iran.

\section{Conflict of interest: None declared.}

\section{References}

1. Shafie B, Baghersalimi S, Barghi V. The association between leadership style and employee performance. Singaporean Journal of Business Economics and Management Studies 2013; 2(5):21-9.
2. Rhoades L, Eisenberger R. Perceived organizational support: a review of the literature. J Appl Psychol 2002; 87(4):698-714.

3. Cho J, Treadway DC. Organizational identification and perceived organizational support as mediators of the procedural justice - citizenship behaviour association: A cross-cultural constructive replication. European Journal of Work and Organizational Psychology 2011; 20(5):631-53.

4. Eisenberger R, Stinglhamber $F$, Vandenberghe $C$, Sucharski IL, Rhoades L. Perceived supervisor support: contributions to perceived organizational support and employee retention. J Appl Psychol 2002; 87(3):565-73.

5. Nayir F. The association between perceived organizational support and teachers' organizational commitment. Eurasian Journal of Educational Research 2012; 48:97-116.

6. Kinicki A, Kreitner R. Organizational behavior: Key concepts, skills \& best practices. 4th ed. New York, United States: McGraw-Hill; 2009.

7. Greenberg J. A taxonomy of organizational justice theories. Acad Manage Rev 1987; 12(1):9-22.

8. Colquitt JA, Conlon DE, Wesson MJ, Porter CO, Ng $\mathrm{KY}$. Justice at the millennium: a meta-analytic review of 25 years of organizational justice research. J Appl Psychol 2001; 86(3):425-45.

9. McDowall A, Fletcher C. Employee development: an organizational justice perspective. Personnel Review 2004; 33(1):8-29.

10. Kim TY, Leung K. Forming and reacting to overall fairness: a cross-cultural comparison. Organ Behav Hum Decis Process 2007; 104(1):83-95.

11. Karriker JH, Williams ML. Organizational justice and organizational citizenship behavior: A mediated multifoci model. Journal of Management 2007; 35(1):112-35.

12. Chughtai AA, Zafar S. Antecedents and consequences of organizational commitment among Pakistani university teachers. Applied H.R.M. Research 2006; 11(1):39-64

13. Bies RJ, Moag JF. Interactional justice: communication criteria of fairness. In: Lewicki RJ, Sheppard BH, Bazerman, MH, editors. Research on negotiations in organizations, Vol 1. 1st ed. Greenwich, Connecticut, United States: JAI Press; 1986. P. 43-55.

14. Starbuck CR. An investigation of the association between follower perceptions of leader openness to experience and follower job satisfaction. Journal of Organizational Culture, Communication and Conflict 2015; 19(1):118-30.

15. Organ DW, Ryan K. A meta-analytic review of attitudinal and dispositional predictors of organizational citizenship behavior. Pers Psychol 1995; 48(4):775-802.

16. Kiakojory K, Jafarnezhad A, Hosseinzadeh SA. The explanation of association between organizational culture and job satisfaction. Journal of Executive Management 2011; 10(2):87-108.

17. Imani J, Aminshayan Jahromi Sh. The association between organizational justice with organizational commitment and job satisfaction among teachers of schools for the Disabled. Journal of Modern Thoughts in Education 2013; 8(2):39-25.

18. Hunter LW, Thatcher SMB. Feeling the heat: effects of stress, commitment, and job experience on job performance. Acad Manage J 2007; 50(4):953-68. 
19. Brown BB. Employees' organizational commitment and their perceptions of supervisors' relations-oriented and task-oriented leadership behaviors. [PhD thesis]. Virginia, United States: Virginia Polytechnic Institute and State University; 2003.

20. Organ DW, Konovsky M. Cognitive versus affective determinants of organizational citizenship behavior. $J$ Appl Psychol 1989; 74(1):157-64.

21. Mowday RT, Steers RM, Porter LW. The measurement of organizational commitment. J Vocat Behav 1979; 14(2):224-47.

22. Asghari E, Khaleghduost T, Asgari F, Khazemnezhad E. Effective factors on nurses' job satisfaction. Journal of Holistic Nursing and Midwifery 2010; 20(2):1-7.

23. Linz SJ. Job satisfaction among Russian workers. Int J Manpow 2003; 24(6):626-52.

24. Raoufi, SY. The association between employee perception of performance evaluation policies with job satisfaction and turnover intention. [MSc thesis]. Rasht: Islamic Azad University of Rasht; 2014.

25. Arshadi N, Shakkarshekan H. Investigating the association between conflict stress and role ambiguity with the performance and job satisfaction of the managers and employees of the National Iranian Oil Company of the South of the South, considering the moderating effect of teamwork and teamwork. [MSc thesis]. Ahvaz: Shahid Chamran University of Ahvaz; 2014.

26. Heidari Z, Askarian M, Davayi M. Association between organizational climate and conflict management teachers' viewpoints. Journal of Modern Industrial/ Organization Psychology 2010; 1(3):65-74.

27. Yousefi Majd F, Sabourifard M, Ghorbanian MR. Investigating the Effect of Organizational Justice Components on Innovative Behavior Case Study: Industrial Town of West Azarbaijan Province. Journal of Behavioral Sciences, 2016; 8(28):47-80.

28. Hassani M, Jodatkordlar L. The study of association between perception of organizational justice with turnover intention, job satisfaction and organizational citizenship behavior of medical staff of Urmia Imam Reza hospital. Journal of Urmia Nursing \& Midwifery Faculty 2012; 10(3):340-52.

29. Sargazi S, Balaghat SR. Organizational justice and its correlation with job satisfaction in employees of Zahedan University of Medical Sciences. Journal of Health Promotion Management 2016; 5(5):1-7.

30. Farzanjou M, Youldoshef, Pardakhtchi M, Fathi Vajargah $\mathrm{K}$. The study of the association between organizational justice, organizational commitment and job satisfaction of faculty members at state and Islamic Azad Universities in Sistan \& Baluchistan. Journal of Management and Planning in Educational Systems 2017; 9(17):41-68.

31. Muqadas F, Rehman CA, Aslam U. Organizational justice and employee's job dissatisfaction: a moderating role of psychological empowerment. Pakistan Business Review 2017; 18(4):848-64.

32. Titrek O, Polatcan M, Gunes DZ, Sezen G. The association among emotional intelligence (EQ), organizational justice (OJ), organizational citizenship behaviour (OCB). International Journal of Academic Research 2014; 6(1 Part B):213-20.
33. AL-Gharaibeh Sh, Albdareen R. Organizational justice and its impact on the commitment of faculty members to work ethics: empirical study on private universities in north provinces. European Journal of Business and Management 2015; 7(12):196-212.

34. Lim BTH, Loosemore M. The effect of interorganizational justice perceptions on organizational citizenship behaviors in construction projects. International Journal of Project Management 2017; 35(2):95-106.

35. Lee KE, Kim JH, Kim MJ. Influence of perceived organizational justice on empowerment, organizational commitment and turnover intention in the hospital nurses. Indian J Sci Technol 2016; 9(20):1-8.

36. Akram MU, Hashim M, Akram Z. Impact of organizational justice on job satisfaction of employees in banking sector of Pakistan. In: Xu J, Nickel S, Machado VC, Hajiyev A, editors. Proceedings of the Ninth International Conference on Management Science and Engineering Management. Advances in Intelligent Systems and Computing, vol 362; 2015 July 21-23; Karlsruhe, Germany; New York, United States: Springer-Verlag Berlin Heidelberg; 2015. P.771-9.

37. Naderi Kh, Arab Z, Badiee H, Ashoori J. The association among management methods, perceived organizational support, organizational commitment and job satisfaction of managers: A case study. Journal of Modern Thoughts in Education 2015; 10(2):103-16.

38. Hosseini kohkamari $P$, Mashallahi A, Bagaie $R$. Mediating role of organizational -based self -esteem on the association of perceived prganizational support with job satisfaction and affective commitment. Journal of Urmia Nursing and Midwifery Faculty 2015; 13(1):55-63.

39. Valipoor Z. The association between perceived organizational supports with organizational citizenship in schools in Sari. Studies of Management and Entrepreneurship 2017; 2(2/4):71-85.

40. Hsiao HC, Chang JC, Chen SC. The influence of support for innovation on organizational innovation: Taking organizational learning as a mediator. The Asia-Pacific Education Researcher 2014; 23(3):46372.

41. Kurtessis JN, Eisenberger R, Ford MT, Buffardi LC, Stewart KA, Adis CS. Perceived organizational support: a meta-analytic evaluation of organizational support theory. J Manage 2017; 43(6):1854-84.

42. Kaffashpor A, Shojaean A, Alaghebandi Hosieni Toosi M. Effect of perceived organizational support on organizational citizenship behaviors with emphasis on the mediating role of job satisfaction. Iranian Journal of Nursing Research 2017; 12(1):42-8.

43. Kwan HK, Liu J, Yim FH-k. Effects of mentoring functions on receivers' organizational citizenship behavior in a Chinese context: a two-study investigation. J Bus Res 2011; 64(4):363-70.

44. Casper WJ, Harris Ch, Taylor-Bianco A, Wayne JH. Work-family conflict, perceived supervisor support and organizational commitment among Brazilian professionals. J Vocat Behav 2011; 79(3):640-52. 